\title{
Independence in the toilet activity in children with myelomeningocele
}

\author{
Marie Donlau ${ }^{1}$, Tor-Björn Falkner², Gunilla Gladh ${ }^{3}$ and Sven Mattsson*3
}

\author{
Address: ${ }^{1}$ Habilitation clinic, LIO, 58225 Linköping, Sweden, ${ }^{2}$ INR University of Linköping, SE 58183 Linköping, Sweden and ${ }^{3}$ IMK, Div. of \\ Pediatrics, University of Linköping, SE 58185 Linköping, Sweden \\ Email: Sven Mattsson* - sven.mattsson@lio.se \\ * Corresponding author
}

from 5 | st Annual Meeting of the Society for Research into Hydrocephalus and Spina Bifida Heidelberg, Germany. 27-30 June 2007

Published: 20 December 2007

Cerebrospinal Fluid Research 2007, 4(Suppl I):S20 doi:I0.I I86/I743-8454-4-SI-S20

This abstract is available from: http://www.cerebrospinalfluidresearch.com/content/4/SI/S20

(c) 2007 Donlau et al; licensee BioMed Central Ltd.

\section{Background}

Most children with myelomeningocele (MMC) have neurogenic bladder dysfunction, with often lifelong needs of treatment making many of them dependent into adulthood. The aim of the present study was to identify and describe deficits in motor respectively executive functions, and time-concept perception hindering independence in the toilet situation for children with MMC treated with clean intermittent catheterisation (CIC) and secondarily to describe their own opinions on how their toilet activity works.

\section{Materials and methods}

In a hospital setting 22 children (11 girls) with MMC and neurogenic bladder dysfunction, 6-19 years old (md $13.1 \mathrm{ys})$ were observed in a toilet visit when performing CIC. Before visiting the toilet the children were asked to rate, using the Canadian Occupational Performance Measurement (COPM), how well they experienced their toilet activity performance and the satisfaction the way they managed it. After the toilet visit a semi-structured interview and an assessment of the time-concept perception (Ka-Tid [1]) were performed.

\section{Results}

Twelve children rated their toilet activity performance as maximally good, as well as the satisfaction the way they managed it. Only five rated themselves as median or below. In contrast the observation showed that just five children were independent and 17 children showed vary- ing motor and/or executive limitations for independence in the toilet activity.

Concerning the time-concept test only two children scored top scores on all items, indicating impaired perception of time since the instrument was developed for children 6-10 years (md 6,1 ys). A significant correlation (Rho $0,675, p=0,001$ ) was found between the degree of independence in the toilet situation and time-concept perception.

\section{Conclusion}

It seems as the children have an unrealistic apprehension of their abilities but how to become independent when not realizing you are dependent? It is important to identify time-concept impairment, in order to offer children means of training and/or compensation with technical aids. To increase the children's awareness of their abilities and limitations in toilet activities, the adoption of a client centred framework is recommended.

\section{References}

I. Janeslätt G, Granlund M, Alderman I, Kottorp A: Evaluating construct validity in a new assessment of time processing ability for children. Scand J Psychol 2007 in press. 